\section{SEXTING: COMPORTAMENTO E IMAGEM DO CORPO}

\author{
SEXTING: BEHAVIOR AND BODY \\ IMAGE
}

\section{Clóvis Wanzinack ${ }^{10}$ Sanderson Freitas Scremin ${ }^{11}$}

Resumo: Sexting é a expressão originada da união de duas palavras em inglês sex (sexo) e texting (envio de mensagens). $\mathrm{O}$ ato consiste em enviar conteúdos provocatórios de caráter sexual, nudismo ou seminudismo, através de textos, fotos, vídeos, via celular ou computador. O objetivo deste artigo foi identificar o grau de participação de acadêmicos/as na prática do Sexting. A metodologia se baseou em pesquisa teórica e empírica, composta por um questionário quantitativo específico elaborado previamente, aplicado a amostragem aleatória de 51 estudantes de um campus universitário. Os resultados revelaram a presença da prática do Sexting no grupo, sendo que $35 \%$ dos sujeitos afirmaram enviar fotos ou vídeos de cunho erótico, enquanto $88 \%$ já receberam tal conteúdo. Particularidades da prática reveladas pelo questionário também são exploradas ao longo do texto, promovendo reflexões sobre o tema.

Palavras Chave: Sexting; Corpo; Comportamento; Imagem; Jovens.

Abstract: Sexting is the term originated from the union of two words in English 'sex' and 'texting' (sending messages). Sexting consists into sending provocative content including sexual, nude or half nude, through texts, photos, videos, via cell phone or computer. The objective of this

\footnotetext{
10 Doutorando e Mestre em Desenvolvimento Regional (FURB), docente da Universidade Federal do Paraná, clovis_cwb@yahoo.com.br

11 Academico do Curso de Graduação em Informática e Cidadania - Universidade Federal do Paraná, sandersonscremin@yahoo.com.br
}

paper was to identify the participation of academics in practices of Sexting. The methodology was based on theoretical and empirical research, based on a specific quantitative questionnaire, previously prepared and applied to random sample of 51 students from a university campus. The results revealed the presence of Sexting practices in the group: $35 \%$ of persons said they already have sent erotic photos or videos, while $88 \%$ have received such content. Peculiarities about this practice revealed by the questionnaire are also discussed throughout the text, promoting reflections about the theme.

Keywords: Sexting; Body; Behavior; Image; Youth.

\section{Introdução}

Nos tempos atuais, em que a tecnologia se faz cada vez mais presente na vida da população mundial, crianças, jovens e adolescentes também adentram no consumo e na utilização de tais modernidades tecnológicas. $\mathrm{O}$ telefone celular deixou de ser uma ferramenta apenas para fazer e receber ligações. Hoje, os celulares além de enviar mensagens, também filmam, capturam fotos e servem como webcam. Existem aplicativos que podem ser instalados no celular para pagar contas on line, marcar encontros, namorar nas redes sociais, cuidar da saúde, ouvir musica e uma imensidade de funcionalidades.

Expor a imagem do corpo, seja por vídeos ou fotos, por email, celular, ou pelas redes sociais, vem se tornando algo corriqueiro na vida de adultos, jovens, adolescentes e até de crianças. Tais mudanças vêm gerando novos hábitos e novos costumes, como a prática do selfie, (ato de tirar fotos de si próprio) e com isso também acarretando algumas complicações na vida desses sujeitos.

Tal prática se multiplica através das páginas e aplicativos de redes sociais como 
Facebook, Twitter, Youtube, Skype, Instagram salas de chats, entre outros. Devido a um desenvolvimento considerável no campo tecnológico, esse avanço permitiu a criação de "apps" (Aplicativos) específicos, que tem funções de conhecer novas pessoas através das redes sociais. Nesse espaço ocorrem trocas de mensagens, textos e algumas vezes conteúdos de conotação sexual, com imagens ou vídeos de semi-nudismo ou nudismo total da própria pessoa, participando ou não de atos sexuais.

Essa prática se intitula como Sexting, que é a expressão originada da união de duas palavras em inglês sex (sexo) e texting (envio de mensagens). $\mathrm{O}$ ato consiste em enviar conteúdos provocatórios de caráter sexual, (nudismo ou seminudismo, em práticas de relações sexuais ou não) através de textos, fotos, vídeos, por meio de celulares, tablets ou computadores.

Alguns aplicativos mais populares, como: Tinder, Grinder, Brenda, Par Perfeito, Whatsapp, entre outros, fornecem subsídios para encontros com pessoas em regiões próximas, funcionamento baseado em sistema de GPS ou radar, detectando pessoas num raio de distância próxima e que estão interessadas em encontros rápidos de sexo casual. Cada vez mais se expõe o corpo nesses aplicativos, geralmente retratado como objeto de desejo e exibicionismo. Também passa a ser visto como forma de aceitação e auxilia no processo de construção da autoestima. Esse ato tem o intuito de conhecer melhor uma pessoa, tentar conquistar, ser almejado ou até mesmo para aumentar a popularidade ou aceitação em seu grupo. Sexting:

Segundo (Barros, 2014), o termo

Surge nos Estados Unidos da América, no século XXI, consiste no envio, compartilhamento e postagem de mensagens eróticas, fotos de corpos desnudos e de vídeos que mostram relações sexuais, ou seja, de materiais que apresentam conteúdos sexuais, sensuais e eróticos, por meio de tecnologias digitais (smartphones, tablets, computadores, e sites de redes sociais, como Facebook, Twitter, etc).

Alguns jovens e adolescentes, na maioria das vezes expõem sua imagem de forma voluntária, basicamente de produção caseira (vídeos e fotos), sem coação de terceiros com a intencionalidade de ser um material privado, ou de divulgação apenas a seus contatos íntimos. Porém em alguns casos, os/as jovens podem se expor por pressões/aceitações de grupos de amigos/as, namorados/as. Também há aqueles/as com a finalidade de seduzir, flertar, paquerar, uma busca pela popularidade, sendo muitas vezes influenciados pela própria mídia.

No entanto, ao compartilhar um desses conteúdos com alguém íntimo/próximo, isso pode ser replicado para terceiros, que replicam para outras pessoas, e assim sucessivamente. Quando esse material se espalha na internet de forma indesejada ou inapropriada pode culminar em sérios problemas emocionais, psicológicos a/o autor/a do conteúdo, e até mesmo chegar a instâncias jurídicas.

Em abril de 2009, nos Estados Unidos, foi realizado um estudo chamado Teen on line \& wireless Safety Survey, Cyberbulling, Sexting and Parental Controls que consistiu em uma entrevista com 655 adolescentes com idade entre 13 a 18 anos, sendo 53\% meninos e $47 \%$ meninas. Nesse estudo consta que 1 (um) em cada 5 (cinco) adolescentes diz já ter se envolvido com a prática do Sexting, seja enviando recebendo, ou compartilhando esse material por email ou celular, de cunho sexualmente sugestivo contendo fotos ou vídeos de nudismo ou seminudismo. Também cita que meninas $(65 \%)$ Sext Senders (quem envia tais mensagens) são mais propensas que meninos (35\%) a enviar sextings. Também cita que a maior porcentagem da prática de Sexter (pessoas envolvidas com sexting) se dá entre jovens 
com idade de $16-18(61 \%)$ e $13-15$ (39\%). (Thomas, 2009).

Uma pesquisa realizada pela SaferNet Brasil 12, em 2009, com 2525 crianças e adolescentes, de faixa etária entre 10 e 17 anos, alunos/as da rede pública e particular, dos Estados do Rio Janeiro, Paraíba, Pará e São Paulo, concluiu que $12,1 \%$ deles/as já publicaram fotos íntimas na internet. (Barros, 2013).

Segundo (Wanzinack, 2014):

Este comportamento de risco entre jovens vem se tornando cada vez mais comum, uma vez que as vítimas, algumas vezes, não têm noção da proporção de comentários ou exposições, que possam se desdobrar decorrentes de sua confiança em outras pessoas, tais como namorados/as ou amigos/as, com os quais compartilham suas fotos e/ou vídeos. Uma parte das fotos ou vídeos que geralmente são compartilhados na internet como forma de cyberbullying são inseridos na internet pelos namorados/as, como forma de chantagens ou vingança, ao fim de um romance. Outra forma utilizada pelos/as agressores/as virtuais, é a invasão virtual de computadores alheios, vasculhando alguma informação, foto ou vídeo, que poderá ser utilizada como moeda

\footnotetext{
12 A SaferNet Brasil é uma associação civil de direito privado, com atuação nacional, sem fins lucrativos ou econômicos, sem vinculação político partidária, religiosa ou racial. Fundada em 20 de dezembro de 2005 por um grupo de cientistas da computação, professores, pesquisadores e bacharéis em Direito, a organização surgiu para materializar ações concebidas ao longo de 2004 e 2005, quando os fundadores desenvolveram pesquisas e projetos sociais voltados para o combate à pornografia infantil na Internet brasileira. Logo que foi criada, a SaferNet Brasil se consolidou como entidade referência nacional no enfrentamento aos crimes e violações aos Direitos Humanos na Internet, e tem se fortalecido institucionalmente no plano nacional e internacional pela capacidade de mobilização e articulação, produção de conteúdos e tecnologias de enfrentamento aos crimes cibernéticos e pelos acordos de cooperação firmados com instituições governamentais, a exemplo do Ministério Público Federal.Fonte: $\quad$ http://www.safernet.org.br/site/ acessado em 08/12/2014.
}

de troca, tanto sexual ou financeira (Wanzinack, 2014, p73).

No Brasil, a lei mais conhecida nesse campo é a Lei $12.737 / 2012^{13}$, elaborada pelo Deputado Paulo Teixeira, e sancionada em 03 de dezembro de 2012. Essa lei coincidiu de ser aprovada logo após um caso emblemático, envolvendo a atriz Carolina Dieckman, que teve 36 fotos íntimas hackeadas (foram apropriadas por um "hacker" pela internet) e espalhadas na rede. Devido ao ocorrido, a lei foi apelidada de "Lei Carolina Dieckman", que dispõe sobre a tipificação criminal de delitos informáticos.

Wanzinack, (2014) cita que:

Esse anonimato muitas vezes potencializa o ataque por parte dos/as agressores/as, por ensejar uma falsa sensação de impunidade. Tal sensação contribui para que o/a agressor/a publique na internet fotos, comentários ou vídeos preconceituosos, que dificilmente teria coragem de falar ou fazer pessoalmente, devido a punições legais ou repreensão das pessoas. Outro grande problema é que alguns/as agressores/as virtuais não tem a mínima noção da dimensão que seus atos podem interferir na vida das pessoas, até pelo fato de não terem uma reposta imediata, o que contribui para o desenvolvimento de uma frieza em suas ações virtuais. (Wanzinack, 2014 p72).

Diante do exposto, foi desenvolvido este estudo, com a finalidade de compreender a prática do Sexting, sua relação com a necessidade da exposição do corpo nas mídias digitais e suas possíveis repercussões entre jovens levando-se em conta as interfaces do uso de tecnologias e redes sociais. A questão trazida a tona neste trabalho configura-se em objeto que dever ser investigado/problematizado, perante a crescente exposição midiática $\mathrm{e}$

13 http://www.planalto.gov.br/ccivil_03/_ato20112014/2012/lei/112737.htm, acessado em 07/12/2014. 
sua relação com a sexualidade dos/as jovens e adolescentes, para que não resulte em transtornos futuros à esses sujeitos.

\section{Metodologia}

O presente estudo teve por objetivo verificar a prevalência do uso das Tecnologias de Informação e Comunicação (TIC's) e das ocorrências de Sexting entre estudantes universitários de um campus de Universidade Federal da região sul do Brasil. A amostra foi constituída por 51 sujeitos que participaram de forma on line da pesquisa. Todos/as declararam estar cientes dos objetivos dessa pesquisa e concordaram com a participação voluntária e anônima na mesma, assinalando o termo de consentimento livre e esclarecido.

Esta pesquisa é caracterizada como exploratória quantitativa, de caráter transversal, pois é a mais adequada para situações em que se pretende mapear e compreender um fenômeno. Utilizou-se o método Survey com desenho interseccional, que limita a adoção de análises descritivas e impede qualquer tentativa de generalização dos resultados e trabalhou-se com amostra não probabilística (ou acidental). (Galani, Machado e Wanzinack, 2014).

Como critérios de inclusão foram considerados: estar regularmente matriculado em curso de graduação da Universidade que sedia esta pesquisa, possuir mais de 18 anos, dispor de meios tecnológicos (computador ou celular) e acesso a internet. Também foi solicitado consentimento da participação na pesquisa, sendo que a mesma foi feita anonimamente, permitindo uma livre expressão dos participantes. Para a coleta dos dados foi elaborado um questionário específico no google docs, sendo que para esta etapa da pesquisa foram aplicadas questões objetivas. A coleta de dados aconteceu online durante o mês de setembro de 2014.
O questionário utilizado neste artigo foi adaptação traduzida livremente para o português pelos autores, de um trabalho de dissertação de mestrado em Educação desenvolvido por René Oswaldo Marrufo Manzanilla, da Universidade Autônoma de Yucatán, México, defendida no ano de 2012.

\section{Discussão dos Resultados}

A prática de Sexting através de artefatos tecnológicos vem inovando as maneiras de exibição do corpo e de vivenciar a sexualidade. Este artigo, de modo algum, busca realizar julgamentos morais sobre a questão. Destacamos que, desde que a prática seja consensual, pode ser uma das maneiras de socializar-se e de exprimir uma sexualidade sadia. Todavia, o que chamamos atenção a partir deste estudo é o fato de que tal prática, apesar de aparentar certa segurança, também pode implicar em riscos. Aparenta segurança, pois se passa em ambientes virtuais e $a$ priori não envolve necessariamente encontros presenciais com desconhecidos. Todavia, os conteúdos trocados no meio virtual e principalmente os conteúdos eróticos enviados de si próprios podem se espalhar pela rede, tornando os indivíduos expostos e gerando consequências que podem repercutir no bem-estar e autoestima.

Nesta pesquisa, realizada com acadêmicos/as matriculados/as em um campus de universidade da região Sul do Brasil, se obteve os seguintes resultados: dos 51 estudantes que responderam ao questionário, a maioria $35(69 \%)$ eram do sexo masculino, e apenas 16 (31\%) do sexo feminino (Fig. 1). A pesquisa contou com amostra aleatória de participantes, tendo sido enviada para mais de 100 acadêmicos/as, divididos de maneira equitativa entre homens e mulheres. Percebeu-se que as mulheres tiveram uma rejeição maior a responder o questionário, 


\section{DIVERS@!}

mesmo havendo explicação de seu anonimato. A faixa etária escolhida para a pesquisa foi acima de 18 anos e até 27

Figura 02: Conhecimento do termo e da prática.

anos. Acredita-se que a menor participação das mulheres seja devido às desigualdades nas relações de gênero, conforme aponta (Scott, 1995), uma vez que tradicionalmente mulheres são colocadas em posição de submissão em relação aos homens. Em outras palavras, se um homem expõe sua intimidade/sexualidade ao participar de uma pesquisa (mesmo que anônima) não é reprimido. Já se uma mulher fizer isso, poderá ser vítima de comentários e preconceitos, o que enfatiza o quanto ainda está se vivendo uma sociedade alicerçada em desigualdades de gênero.

\section{Antes da explicação do questionário, você sabia dizer o que é Sexting?}

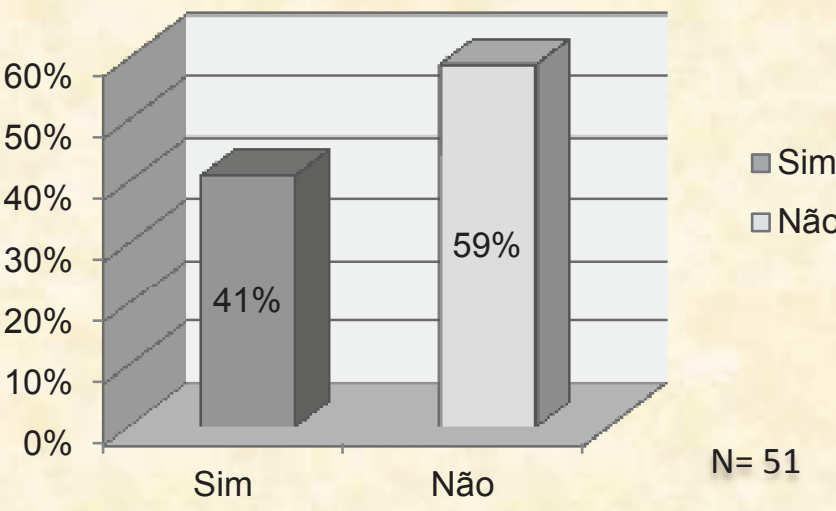

Figura 01: Gênero.

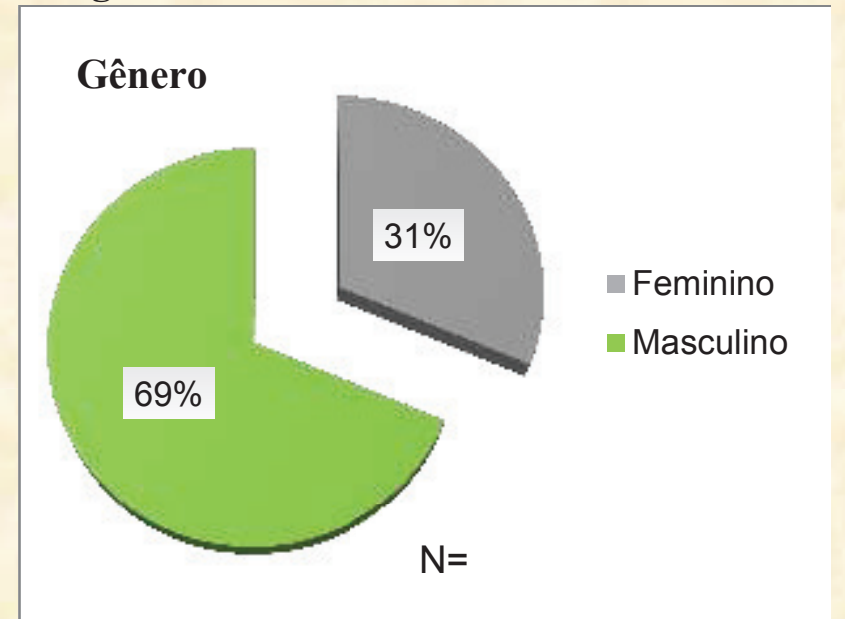

Fonte: autores, 2014

Ao perguntar se os acadêmicos tinham familiaridade com o termo Sexting, de um total de 51 questionários, 30 (59\%) dos/as entrevistados/as desconhecem o termo, mesmo que alguns/as revelaram que possuem comportamentos e práticas de envio e recebimento de mensagens, fotos e vídeos com conteúdo sexual, erótico, de nudez e ou semi-nudez. Após esta pergunta, foi explicado no próprio questionário conceitualmente o termo Sexting, para dar continuidade enfatizando outras questões.
Fonte: autores, 2014

Ao perguntar sobre os aplicativos mais utilizados nos celulares, a grande maioria afirmou ter cadastro em programas como Facebook (98\%), Whatsapp (88\%), Youtube (73\%), Instagram (57\%), Twitter (43\%), entre outros (25\%), como Grindr, Scruff, Skype, Par Perfeito, entre outros.

Segundo o site Alexa Analytics ${ }^{14} \mathrm{o}$ Facebook é a maior e mais acessada rede social do Brasil e do mundo, conectando pessoas, amigos com compartilhamentos de fotos, links e vídeos. Entre as páginas mais acessadas no Brasil, o Youtube é a quarta no ranking nacional.

Em relação aos aplicativos mais baixados no Brasil, segundo site da Apple "iTunes Charts" em primeiro lugar está o Whatsapp, seguido do Messenger, Facebook, Instagram e em quinto lugar o Youtube.

\footnotetext{
${ }^{14}$ A Alexa Analytics é um serviço gerenciado pela Amazon, que analisa e elabora rankings dos sites mais acessados, segundo dados da ferramenta Alexa Toolbar. Fonte: http://www.alexa.com/topsites/countries;o/BR. Acessado em 08/12/2014.

${ }^{15} \mathrm{https}: / /$ www.apple.com/br/itunes/charts/freeapps/, acessado em 08/12/2014
} 


\section{DIVERSQ!}

Figura 03: Aplicativos mais utilizados.

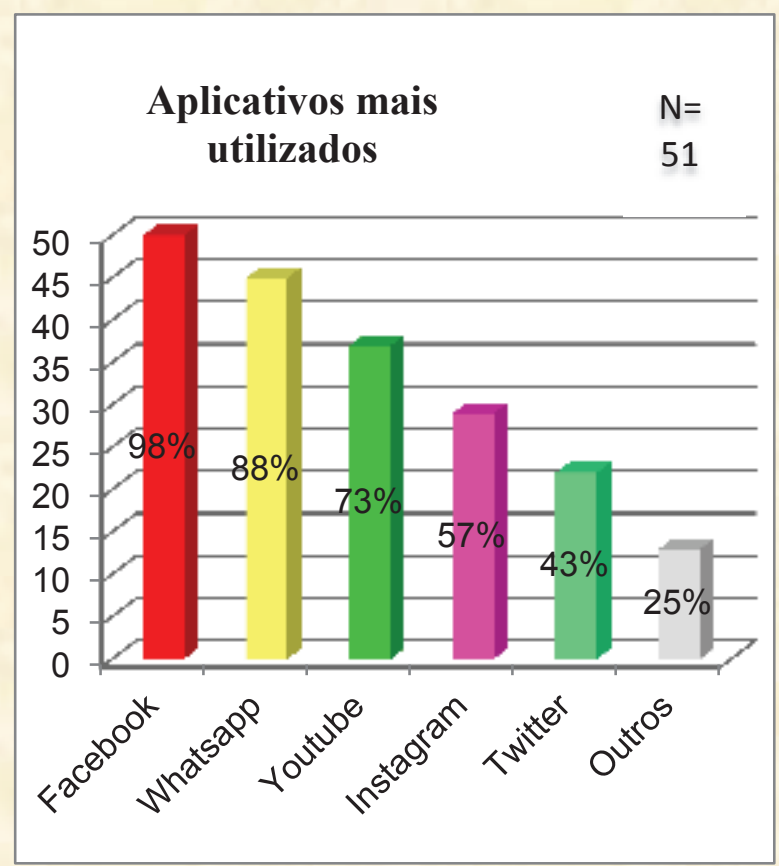

Fonte: autores, 2014

$\mathrm{Na}$ figura 4, está demonstrado que neste estudo, de um $n=51,18(35 \%)$ dos/as entrevistados/as praticam ou já praticaram o Sexting. Uma pesquisa publicada em dezembro de 2008 comprovou que, nos EUA, 20\% dos jovens entre 13 e 19 anos já enviaram imagens pelo celular de si mesmo nu ou seminu. Entre os jovens de 20 e 26 anos a proporção chega a 33\%. No Brasil, no entanto, o fenômeno é recente, mas tem crescido rapidamente. Segundo a Safernet, ONG relacionada à defesa dos direitos humanos na Internet, em uma pesquisa feita pela entidade, com 2.525 crianças e adolescentes brasileiros em 2009, revelou que já naquela época $12 \%$ deles/as admitiram ter publicado fotos íntimas na internet. (Conte e Rossini, 2010).
Figura 04: Já enviou uma foto ou vídeo com imagens de nudismo ou semi nudismo de si mesmo a alguém (via celular)?

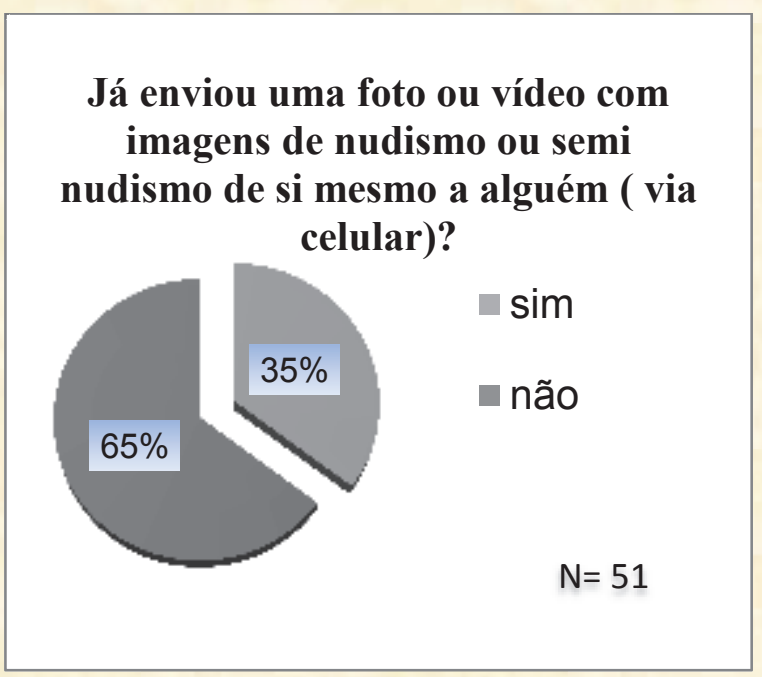

Fonte: autores, 2014

Percebe-se nessa questão nitidamente que o recebimento de mensagens contendo fotos ou vídeos com conotação sugestiva sexual é muito maior que o envio. De um $n=51,45$, que correspondem a $88 \%$ dos entrevistados/as afirmaram já ter recebido fotos ou vídeos de nudismo ou semi nudismo. Este pode ser um indicativo, talvez por possuírem idade entre 18 e 27 anos, de que os sujeitos participantes deste estudo, demonstraram um receio maior no envio de sextings do que no recebimento, preservando em certa medida a sua privacidade.

No estudo percebe-se claramente que a prática de Sexting vem aumentando entre os jovens, e pouco ainda se discute sobre tais implicações psicológicas que tal fato acarreta. Uma vez que fotos, vídeos são socializados/compartilhados na internet, dificilmente serão deletadas/apagadas por completo. 
Figura 05: Já recebeu uma foto ou vídeo com imagens de nudismo ou semi nudismo de alguém (via celular)?

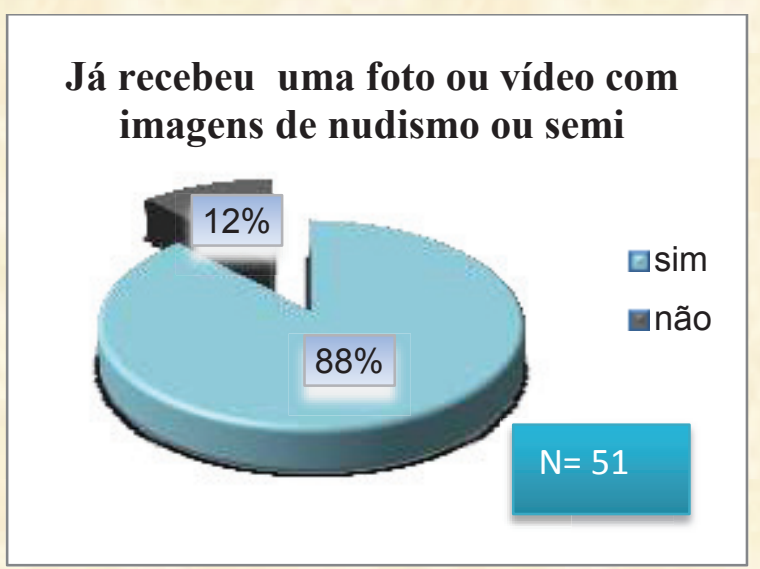

Fonte: autores, 2014

Tais fotos e vídeos feitos/criados por jovens e adolescentes podem alimentar a indústria pornográfica e disseminar-se em vários sites sem o consentimento da vítima. Em alguns casos podem aparecer em redes sociais como formas de ridicularizarão/perseguição da vitima, caracterizando casos de cyberbullying. Em casos mais graves, diante do desespero da vitima, tais situações podem culminar até em suicídio.

Segundo Gomes e Sanzovo (2013), umas das principais preocupações do Cyberbullying, que as vítimas não possuem nenhum lugar seguro para evitar as agressões virtuais, visto que pode ser atacada a qualquer momento, qualquer hora, em qualquer lugar, até mesmo em seu próprio quarto da casa. Seu poder de compartilhamento da informação pode potencializar ainda mais, ao expor tais fotos/redes sociais, ampliando cada vez mais, com mais telespectadores, intensificando a ofensa e multiplicando o ato de violência. Contendo vários agressores ao mesmo tempo, enviando mensagens de cunho malicioso, fica cada vez mais difícil identificar o autor inicial da violência e responsabilizar/punir os responsáveis.

\section{Considerações Finais}

Devido aos altos índices de recebimento de fotos/vídeos de cunho erótico é possível comparar o aumento da prática com o crescimento significativo do Sexting na atualidade e consequentemente refletindo sobre os dados brasileiros. O Sexting é uma prática que vem se propagando cada vez mais entre crianças, jovens e adolescentes no meio virtual. Passamos de um modelo de educação demasiado normativa (com princípios de valores rígidos), para outra abordagem permissiva $\mathrm{e}$ às vezes um tanto desequilibrada em meio aos cenários digitais. Educar não é somente informar, mas sim orientar e transmitir valores que possam ajudar esses jovens a realizar escolhas responsáveis e saudáveis. O bom diálogo e orientação, em qualquer geração, é o melhor caminho para um desenvolvimento sadio e seguro. Mais importante que proibir é orientar.

Com a finalidade de preservar a integridade moral e física dos jovens, e garantir seu sadio desenvolvimento, diversas iniciativas jurídicas são tomadas em várias partes do mundo. Em 2009, foi elaborado o Memorandum de Montevideo ${ }^{16}$, com normas e recomendações para se garantir a segurança e integridade de jovens e adolescentes da América Latina, nas redes sociais e Internet. Umas das principais preocupações que pais e educadores possuem em relação aos jovens na Internet, é o risco da pedofilia e o cyberbullying.

Como diz um trecho do Memorandum de Montevideo citado por

\footnotetext{
${ }^{16}$ Protección de datos personales de menores en Internet Presentación del Memorándum sobre la protección de datos personales y la vida privada en las redes sociales en Internet, en particular de niños, niñas y adolescentes (3 de diciembre de 2009 Ciudad de México)
}

http://memorandumdemontevideo.ifai.org.mx/ acessado em $08 / 12 / 2014$ 
(Manzanilla, 2012), a participação anônima e o uso de pseudônimos são possíveis nas redes sociais digitais. $\mathrm{O}$ processo educativo deve refletir sobre os aspectos positivos de seu uso como meio de proteção, e um uso responsável, que dentre outras coisas, implica em não utilizar pseudônimos para enganar ou confundir outros sobre sua identidade real.

Deve-se advertir do perigo que é o chamado roubo ou substituição de identidade, que pode produzir nos meios digitais que induzem o engano. Não há dúvidas que essa nova geração está cada vez mais entrosada com as novas tecnologias, e por esse motivo, é indispensável orientá-los que nem todo mundo que está do outro lado da tela pode possuir boas intenções.

Nesses tempos em que a tecnologia é quase onisciente, educar e orientar os jovens sobre os riscos e perigos ocultos da internet é algo essencial para o sadio desenvolvimento dos mesmos. Muitos pais e educadores, no entanto, sentem dificuldade em acompanhar os jovens, que assimilam as novas tecnologias a uma velocidade assombrosa.

\section{Referências}

BARROS, S. D. C. Discutindo sobre Sexting. Revista Diversidade e Educação. Rio Grande - RS: Joanalira Corpes Magalhães: 02 p. 2013.

Sexting na adolescência: análise da rede de enunciações produzida pela mídia. 2014. 188 (Doutorado). Programa de Pós-Graduação em Educação em Ciências: Química da Vida e Saúde, Universidade Federal do Rio Grande FURG, Rio Grande - RS.

CONTE, C. P.; ROSSINI, A. E. D. S. Aspectos Jurídicos do Cyberbullying. Revista FMU Direito, n. 34, p. 20, 2010.

GALANI, S. P.; MACHADO, A. E. F.; WANZINACK, C. O Uso das TIC's e o
Cyberbullying: Um Estudo Realizado com Escolares do Município de Paranaguá/PR $33^{\circ}$ Congresso Brasileiro de Informática na Educação (CBIE 2014)20a Workshop de Informática na Escola (WIE 2014). Dourados, MS: 352-359 p. 2014.

GOMES, L. F.; SANZOVO, N. M. Bullying e prevenção da violência nas escolas: quebrando mitos, construindo verdades. São Paulo: Saraiva, 2013. 239.

MANZANILLA, R. O. M. Surgimiento y proliferación del sexting. Probables causas y consecuencias en adolescentes de secundaria. 2012. 63 (Maestria en Educacion). Facultad de Educacion, Universidad Autonoma de Yucatán, Mérida, Yucatán - México.

SCOTT, J. W. Gênero: Uma categoria útil de análise histórica. Educação e Realidade, v. 20, n. 2, p. 29, 1995.

THOMAS, K. Teen on line \&amp; wireless Safety Survey, Cyberbulling, Sexting and Parental Controls Cox Communications Teen Online \& Wireless Safety Survey, p.59. 2009

WANZINACK, C. Bullying e cyberbullying: faces silenciosas da violência. In: SIERRA, J. C. e SIGNORELLI, M. C. (Ed.). Diversidade e Educação: interseccções entre corpo, gênero e sexualidade, raça. Matinhos: UFPR LITORAL, 2014. cap. 1.4, p.67-82. 